\title{
Botulinum Toxin A (BTA) Use in Abdominal Wall Re- construction: Initial Series and Early Results
}

\author{
Gbalekan Dawodu*, Abraham Katz, Giulianna Cupello, John McAuliffe and Flavio Malcher \\ Albert Einstein College of Medicine/Montefiore Medical Center, USA \\ *Corresponding author: Gbalekan Dawodu, Albert Einstein College of Medicine/Montefiore Medical Center, New York, USA
}

\begin{tabular}{|c|c|}
\hline ARTICLE INFO & ABSTRACT \\
\hline Received: 慧 April 23, 2019 & Citation: Gbale S, Dawodu, Abraham Katz, Giulianna Cupello, John McAuliffe, Flavio Malch- \\
\hline Published: April 30, 2019 & $\begin{array}{l}\text { er. Botulinum Toxin A (BTA) Use in Abdominal Wall Reconstruction: Initial Series and Early } \\
\text { Results. Biomed J Sci \& Tech Res 17(4)-2019. BJSTR. MS.ID.003030. }\end{array}$ \\
\hline
\end{tabular}

\section{Introduction}

Abdominal wall hernias are one of the most common clinical conditions faced by general surgeons. They can occur in up to $28 \%$ of patients undergoing abdominal surgery, with studies indicating incisional hernias in at least $10 \%$ of all open abdominal surgical procedures [1-3]. In the United States, this translates to approximately 200,000 incisional hernia repairs performed annually [4] Incisional hernias result from the disruption of the abdominal myofascial anatomy during surgical intervention, which modifies the dynamic forces within the abdominal wall muscles [5] This creates a markedly increased lateral traction and midline shift which can further enhance the hernia. Thus, methods to reduce tension before and during surgical procedures have been researched and applied over the last decade. One of the novel methods is Botulinum Toxin A (BTA) injection to lateral abdominal musculature. BTA is a neurotoxic protein that predominantly inhibits release of acetylcholine endosomes at the pre-synaptic cholinergic nerve terminal. This temporarily blocks signal transmission in both motor and autonomic innervation, resulting in flaccid paralysis of skeletal muscles [6,7] The paralysis reaches its maximum effect approximately 4 weeks after BTA administration and decreases gradually after 2.5 months, persisting until 4-6 months after initial injection.

The agent also presents analgesic properties due to its capacity of blocking the release of pain mediator (substance P and calcitonin gene related peptide) endosomes. Since it was first approved by the FDA in 1989, BTA has been used to treat various medical conditions including: dystonia, spasticity, cerebral palsy, hyperhidrosis, hypersalivation, bladder dysfunction, and skin wrinkles $[8,9]$ More recently, human and animal studies have tested BTA use perioperatively. The main goals were, among others: to decrease lateral traction before surgical hernia repair and postoperative pain $[10,11]$. Decreasing lateral tension is important especially when complex hernias are being treated. Complex hernias include hernias larger than $10 \mathrm{~cm}$, patients presenting with loss of domain, and multiple comorbidities, among other criteria. 12 By allowing repair under less tension, injection of BTA is expected to decrease the rate of hernia recurrence. We sought to evaluate the efficacy of BTA injection pre operatively in patient planned to undergo an incisional hernia repair.

\section{Methods}

\section{Patient Selection}

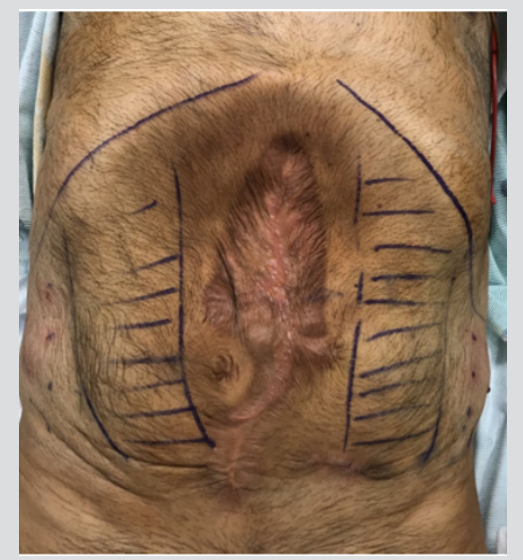

Figure 1: Image of patient with wide defect $(17 \mathrm{~cm})$ without loss of domain with rectus identified and marked and injection points on the lateral muscles. 
Patients were selected for preoperative BTA injection based on the following criteria: width of the hernia defect over $15 \mathrm{~cm}$ (Figure 1) and/or suspected loss of domain (Figure 2) with inability to achieve primary closure during hernia repair.

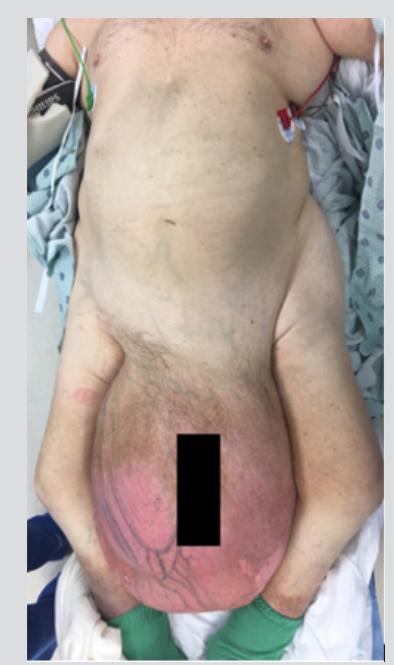

Figure 2: Gigantic right inguinal hernia with loss of domain

\section{Protocol}

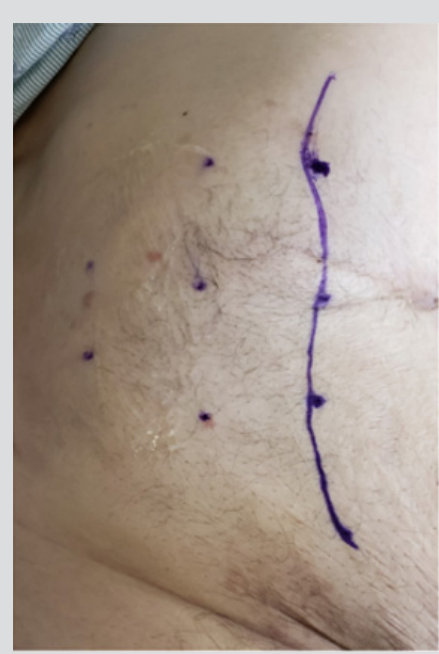

Figure 3: BTA injection sites on right anterior axillary line (3) and mid axillary line (2). Semilunar line drawn.

BTA Injection: Injection was performed by the operative surgeon with the patient in supine position under ultrasound guidance. Injection sites were marked lateral to the semilunaris line with 3 sites on the anterior axillary line and 2 at the mid axillary line, as described by Ibarra (Figure 3). The area was prepped and draped with sterile technique which was followed by injection of BTA under ultrasound guidance (Figure 4). The site of injection was the plane between the internal oblique and transverse muscles (Figure 5). $200 \mathrm{UI}$ of BTA were diluted in $20 \mathrm{cc}$ of saline and $2 \mathrm{cc}$ (20 UI) were injected at each of the 10 injection sites. After the procedure, the patients were either discharged safely home or remained in-patient depending on their prior admission status. 3 out of 4 patients underwent simultaneous diagnostic laparoscopy; at which time they received intra-abdominal catheter insertion for progressive preoperative pneumoperitoneum due associated loss of domain. Following injection of BTA, patients were taken to the operating room to undergo planned repair of the hernia between 2 and 5 weeks. The maximum effect of paralysis from BTA is usually obtained around 4 weeks, but some effect may be seen after only a few days (Figure 6).

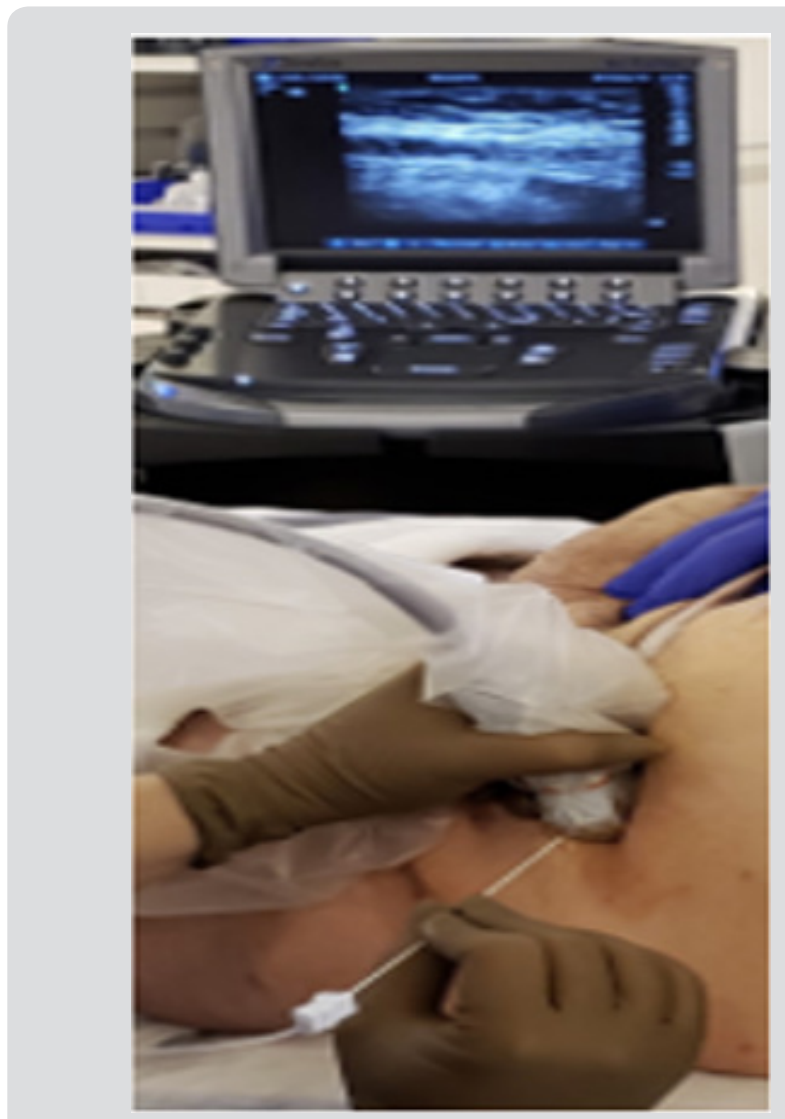

Figure 4: Ultrasound guided injection of BTA into the lateral abdominal wall.

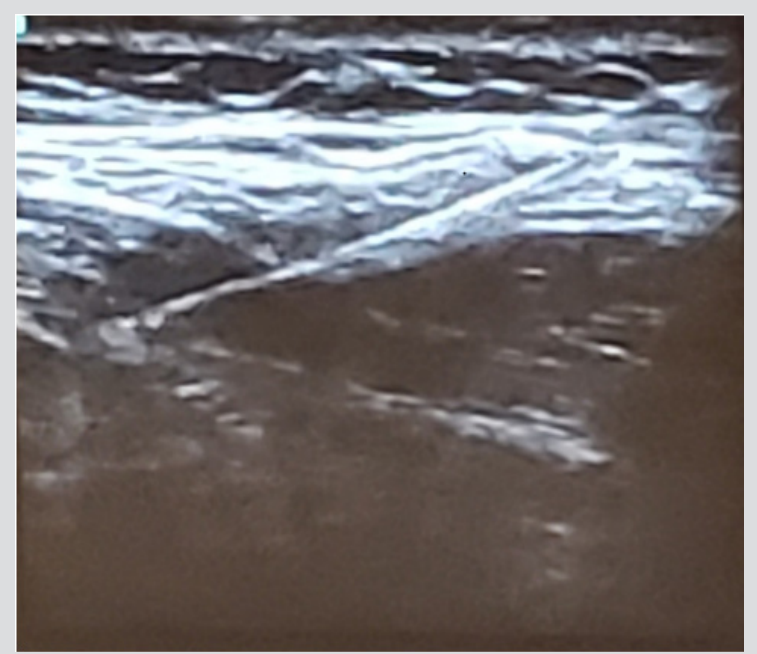

Figure 5: $20 \mathrm{U}$ of BTA injected, on each site, between transverse abdominis and the internal oblique. 


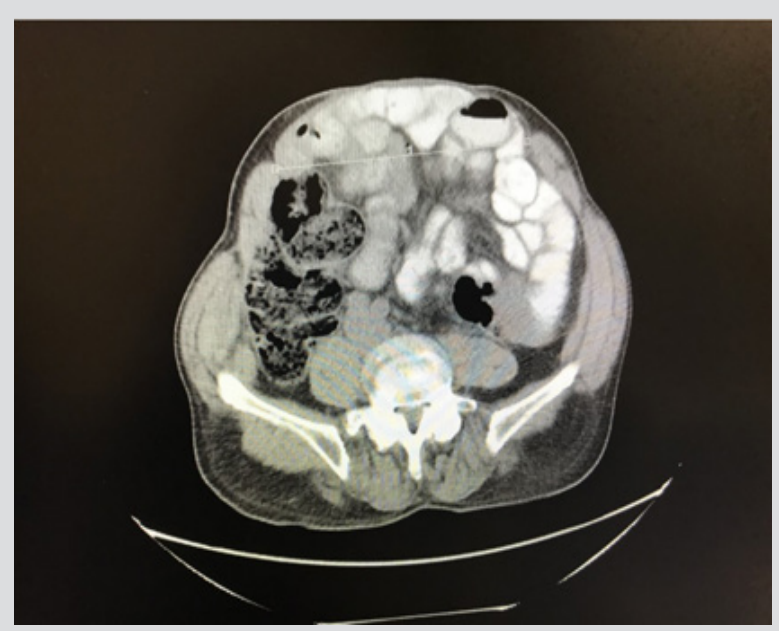

Figure 6A: $17 \mathrm{~cm}$ wide defect prior to BTA injection.

\section{Results}

A surgical repair with primary closure of the midline and/ or defect was possible in all the patients without requiring the use of bridging mesh. The average operative time was 178 mins. All patients underwent repair with mesh placement in an onlay or sublay position. During hernia repair, 3 out of the 4 patients underwent simultaneous surgical procedures. Colostomy closure was performed in the same surgical event in one patient.

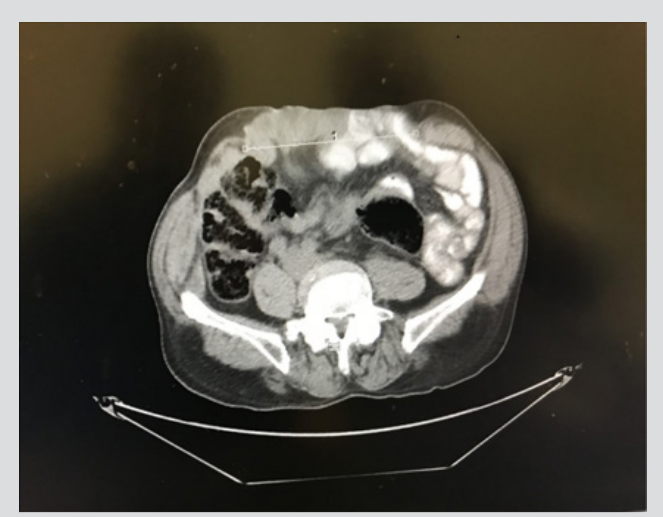

Figure 6B: Same CT imaging illustrating $13 \mathrm{~cm}$ hernia defect 3 weeks following $200 \mathrm{u}$ BTA injection (>20\% reduction) besides clear change of abdominal conformation, with reduced viscera.

Component Separation (CS) was performed in 2 out of 4 patients, but surprisingly, the widest defect $(23 \mathrm{~cm})$ did not required CS to be closed. Length of stay of patients post procedurally was between 2-28 days. 1 out of 4 patients post-operative course was complicated by SSI and another presented with skin dehiscence at the panniculectomy incision. No injection related complications as hematoma or abscess were reported. No systemic effects of BTA were found (Table $1 \& 2$ ).

Table 1: Patient characteristics.

\begin{tabular}{|c|c|c|c|c|}
\hline Patient Characteristics & 1 & 2 & 3 & 4 \\
\hline Age & 72 & 77 & 58 & 63 \\
\hline Sex & M & $\mathrm{F}$ & M & $\mathrm{F}$ \\
\hline Comorbidities & $\mathrm{N}$ & $\begin{array}{l}\text { COPD, Asthma, HTN, } \\
\text { HLD, GERD, EtOH abuse, } \\
\text { Colonic perforation. }\end{array}$ & HIV, Diverticulitis & $\begin{array}{l}\text { DM, HLD, CAD, OSA, } \\
\text { Morbid Obesity }\end{array}$ \\
\hline PSH & $\mathrm{N}$ & Colostomy, Tracheostomy & $\begin{array}{c}\text { Colostomy, Colostomy } \\
\text { reversal }\end{array}$ & $\begin{array}{l}\text { Exploratory laparotomy, } \\
\text { Cholecystostomy }\end{array}$ \\
\hline \multicolumn{5}{|l|}{ Hernia attributes } \\
\hline Location & inguinal & ventral & ventral & ventral \\
\hline Size $(\mathrm{cm})$ & $9 \times 7.5$ & $20 \times 12$ & $25 \times 15$ & $30 \times 23$ \\
\hline Loss of Domain & $\mathrm{Y}$ & Y & $\mathrm{N}$ & Y \\
\hline
\end{tabular}

Table 2: Operative outcomes.

\begin{tabular}{|c|c|c|c|c|}
\hline Operative Outcomes & 1 & 2 & 3 & 4 \\
\hline \multicolumn{5}{|l|}{ Repair Attributes } \\
\hline Intraoperative time (mins) & 115 & 166 & 144 & 288 \\
\hline Mesh position & sublay & onlay & sublay & onlay \\
\hline Component separation & $\mathrm{N}$ & $\mathrm{Y}$ & $\mathrm{Y}$ & $\mathrm{N}$ \\
\hline Concomitant procedure & Scrotoplasty & $\begin{array}{c}\text { Colostomy closure, } \\
\text { Parastomal Hernia repair }\end{array}$ & $\mathrm{N}$ & $\begin{array}{l}\text { Appendectomy, } \\
\text { Panniculectomy, } \\
\text { Cholecystectomy }\end{array}$ \\
\hline \multicolumn{5}{|l|}{ Outcomes } \\
\hline LOS; post-procedure (days) & 5 & 28 & 2 & 13 \\
\hline Complications & $\mathrm{N}$ & Post-operative ileus, SSI & $\mathrm{N}$ & Skin dehiscence \\
\hline Length of follow-up & 8 & 5 & 1 & 2 \\
\hline
\end{tabular}




\section{Discussion}

Traditionally, reconstructive techniques for large ventral hernias employed methods such as mesh bridging and component separation 13. Bridging has the drawback that the muscular function of the abdominal wall is not corrected as well as unacceptable recurrence rates. [14] Component Separation (CS), although effective, involves extensive tissue dissection. CS is has been shown to be associated with complications such as flap necrosis, wound infection, wound dehiscence, and hematoma and seroma formation [15-22]. Since Ibarra et al. [23] first description of this technique in 2009, various groups have studied the administration of BTA prior to abdominal wall hernia repair. Ibarra described a significant decrease in thickness and an increase in length of lateral abdominal wall muscles after the application of BTA. These muscular changes are the result of the muscle paralysis and regression of the contraction and lateral retraction process, which can be visualized by CT scan after 4 weeks of BT injection. Zielinski et al. [24] reported a retrospective review of their results of BT injection in patients treated with open abdomen after a damage control laparotomy. All patients were treated with negative pressure dressings for temporary abdominal closures until primary fascial closure was performed.

In $83 \%$ of these patients, within 24 hours of the initial open abdomen procedure, primary fascial closure was achieved, with a partial closure with absorbable mesh supported by $6 \%$. The ideal objective is to perform a tension-free closure, with abdominal wall dynamic stability and optimized aesthetic appearance [25]. Besides been described as one of the techniques to achieve primary fascial closure in patients with complex incisional hernias with loss of domain, BTA administration is also associated with decreased morbidity of abdominal wall reconstruction by reducing the risk of compartment syndrome [26]. BTA has also been described in association with various techniques to similarly achieve primary closure of complex abdominal wall hernias as Preoperative Progressive Pneumoperitoneum (PPP) as initially described by Moreno [27], With PPP the abdominal cavity can be expanded allowing for reduction of large volume hernias as well as improving postoperative respiratory function. The increased abdominal cavity volume also reduces the risk of Abdominal Compartment Syndrome (ACS), the major problem in large incisional hernia repair $[28,29]$. The effects of PPP may be further complemented by BTA, as it appears it would even allow us to handle larger volumes of insufflation by relaxing the abdominal wall muscles temporarily. Elstner et al. [30], described a potential advantage of the combination PPP with BTA; the use of neurotoxin would allow an abbreviated duration of PPP, as the gradual stretching process of the abdominal wall is greatly accelerated by the preexisting flaccid paralysis of the lateral abdominal musculature.

\section{Conclusion}

BTA appears to be a safe and useful adjunct to achieve primary fascial closure in complex abdominal wall hernias. BTA can be considered to limit the need for bridging meshes and need for component separation. No complications were encountered with BTA injection and primary closure was achieved in all cases. Current literature, however, has significant limitations as most studies are retrospective case series of varying quality. As a promising adjunct or possibly pre-operative standard of care it is imperative that longterm high quality studies be conducted to for comparative cohort data on indication, application techniques, dosing, efficacy, safety, and costs. Consequently, objectively comparing BTA with similar potential pre-operative adjunctive therapies should also be the aim of future studies.

\section{References}

1. DuBay DA, Wang X, Adamson B, Kuzon WM, Dennis RG, et al. (2005) Progressive fascial wound failure impairs subsequent abdominal wall repairs: A new animal model of incisional hernia formation. Surgery 137: 463-471.

2. Millikan KW (2003) Incisional hernia repair. Surgical Clinics of North America 83: 1223-1234.

3. Mudge M, Hughes LE (1985) Incisional hernia: A 10 year prospective study of incidence and attitudes. Br J Surg 72: 70-71.

4. (1995) National Hospital Discharge Survey, Ann Arbor, Mich: InterUniversity Consortium for Political and Social Research [distributor]; 1998.

5. Levine J, Karp N (2001) Restoration of abdominal wall integrity as a salvage procedure in difficult recurrent abdominal wall hernias using a method of wide myofascial release. Plast Reconstr Surg 107(3): 717-718.

6. Göbel H, Heinze A, Reichel G, Hefter H, Benecke R (2006) Dysport myofascial pain study group. Efficacy and safety of a single botulinum type A toxin complex treatment (Dysport) for the relief of upper back myofascial pain syndrome: Results from a randomized double-blind placebo controlled multicentre study. Pain. Nov 125(1-2): 82-88.

7. Smoot D, Zielinski M, Jenkins D, Schiller H (2011) Botox A injection for pain after laparoscopic ventral hernia: a case report. Pain Med Jul 12(7): 1121-1123.

8. Dressler D (2012) Clinical applications of botulinum toxin. Curr. Opin. Microbiol 15: 325-336.

9. Barwood S, Baillieu C, Boyd R, Brereton K, Low J, et al. (2000) Analgesic effects of botulinum toxin A: A randomized, placebo-controlled clinical trial. Dev. Med. Child. Neurol 42: 116-121.

10. Ibarra Hurtado TR, Nuno Guzman CM, Echeagaray Herrera JE, Robles Velez E, de Jesus Gonzalez Jaime J (2009) Use of botulinum toxin type A before abdominal wall hernia reconstruction. World J. Surg 33:25532556.

11. Cakmak M, Caglayan F, Somuncu S, Leventoglu A, Ulusoy S, et al. (2006) Effect of paralysis of the abdominal wall muscles by botulinum A toxin to intraabdominal pressure: an experimental study. J Pediatr. Surg 41: 821-825.

12. Slater NJ, Montgomery A, Berrevoet F, Carbonell AM, Chang A, et al. (2014) Criteria for definition of a complex abdominal wall hernia. Hernia 18: 7-17.

13. Elstner KE, Read JW, Saunders J (2019) Hernia.

14. Awad ZT, Puri V, LeBlanc K, Stoppa R, Fitzgibbons RJ, et al. (2005) Mechanisms of ventral hernia recurrence after mesh repair and a new proposed classification. J Am Coll Surg 201: 132-140.

15. Deerenberg EB, Timmermans L, Hogerzeil DP, Slieker JC, Eilers PH, et al. (2015) A systematic review of the surgical treatment of large incisional hernia. Hernia 19: 89-101.

16. Ramirez OM, Ruas E, Dellon AL (1990) Components Separation method for closure of abdominal-wall defects: an anatomic and clinical study. 
Plast Reconstr Surg 86: 519-526.

17. Heller L, McNichols CH, Ramirez OM (2012) Component separations. Semin Plast Surg 26: 25-28.

18. Heller L, Chike-Obi C, Xue AS (2012) Abdominal wall reconstruction with mesh and components separation. Semin Plast Surg 26: 29-35.

19. Saulis AS, Dumanian GA (2002) Periumbilical rectus abdominis perforator preservation significantly reduces superficial wound complications in separation of parts hernia repairs. Plast Reconstr Surg 109:2275-2282.

20. Lowe JB, Garza JR, Bowman JL, Rohrich RJ, Strodel WE (2000) Endoscopically assisted "components separation" for closure of abdominal wall defects. Plast Reconstr Surg 105: 720-729.

21. Maas SM, de Vries Reilingh TS, van Goor H, de Jong D, Bleichrodt RP (2002) Endoscopically assisted components separation technique for the repair of complicated ventral hernias. J Am Coll Surg 194: 388-390.

22. Rosen MJ, Williams C, Kin J, McGee MF, Schomisch S, et al. (2007) Laparoscopic versus open-component separation: a comparative analysis in a porcine model. Am J Surg 194: 385-389.

23. Zielinski MD, Goussous N, Schiller HJ (2013) Hernia 17: 101.

24. Mathes SJ, Steinwald PM, Foster RD, Hoffman WY, Anthony JP (2000) Complex abdominal wall reconstruction: A comparison of flap and mesh closure. Ann Surg 232: 586-596.

\section{ISSN: 2574-1241}

DOI: 10.26717/BJSTR.2019.17.003030

Gbalekan Dawodu. Biomed J Sci \& Tech Res

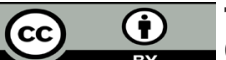

This work is licensed under Creative Commons Attribution 4.0 License

Submission Link: https://biomedres.us/submit-manuscript.php
25. Kirkpatrick AW, Nickerson D, Roberts DJ, Rosen MJ, McBeth PB (2017) Intra-Abdominal Hypertension and Abdominal Compartment Syndrome after Abdominal Wall Reconstruction: Quaternary Syndromes?. Scand J Surg 106(2): 97-106.

26. Goñi Moreno I (1947) Chronic eventrations and large hernias: preoperative treatment by progressive pneumoperitoneum-original procedure. Surgery 22: 945-953.

27. Quarishi AH, Borkar MM, Mastud MM, Jannawar GG (2013) Preoperative progressive pneumoperitoneum for repair of a large incisional hernia. Updates Surg 65: 165-168.

28. Dumont F, Fuks D, Verhaeghe P, Brehant O, Sabbagh C, et al. (2009) Progressive pneumoperitoneum increases the length of abdominal muscles. Hernia 13: 183-187.

29. Bueno Lledó J, Torregrosa A, Ballester N (2017) Hernia 21: 233.

30. Elstner KE, Read JW, Rodriguez Acevedo O, Ho Shon K, Magnussen J, et al (2017) Preoperative progressive pneumoperitoneum complementing chemical component relaxation in complex ventral hernia repair. Surg Endosc 31: 1914-1922.

$\begin{array}{ll}\text { BIOMEDICAL } & \text { Assets of Publishing with us } \\ \text { RESEARCHES } & \text { - Global archiving of articles } \\ \text { ISSN: 2574-1241 } & \text { - Immediate, unrestricted online access } \\ & \text { - Rigorous Peer Review Process } \\ \end{array}$

